\title{
ON THE BIRTH OF SOME PROTON-FLARE REGIONS*
}

\author{
T. FORTINI and M. TORELLI \\ (Osservatorio Astronomico Monte Mario, Roma, Italy)
}

\begin{abstract}
A BSTRACT
Observations of the birth of some proton-flare regions show that they originate in two or more close active centers.

On our study on the birth and the development of the Calcium plage (McMath 8362) of the proton event of July 7, 1966 (Fortini and Torelli, 1968), we have realized that it was formed by the merging of two different elements - both born on the solar disk - with a difference in time of approximately 80 hours. The first center, using the terminology suggested by R. Michard (Martres et al., 1966), was born at the periphery
\end{abstract}

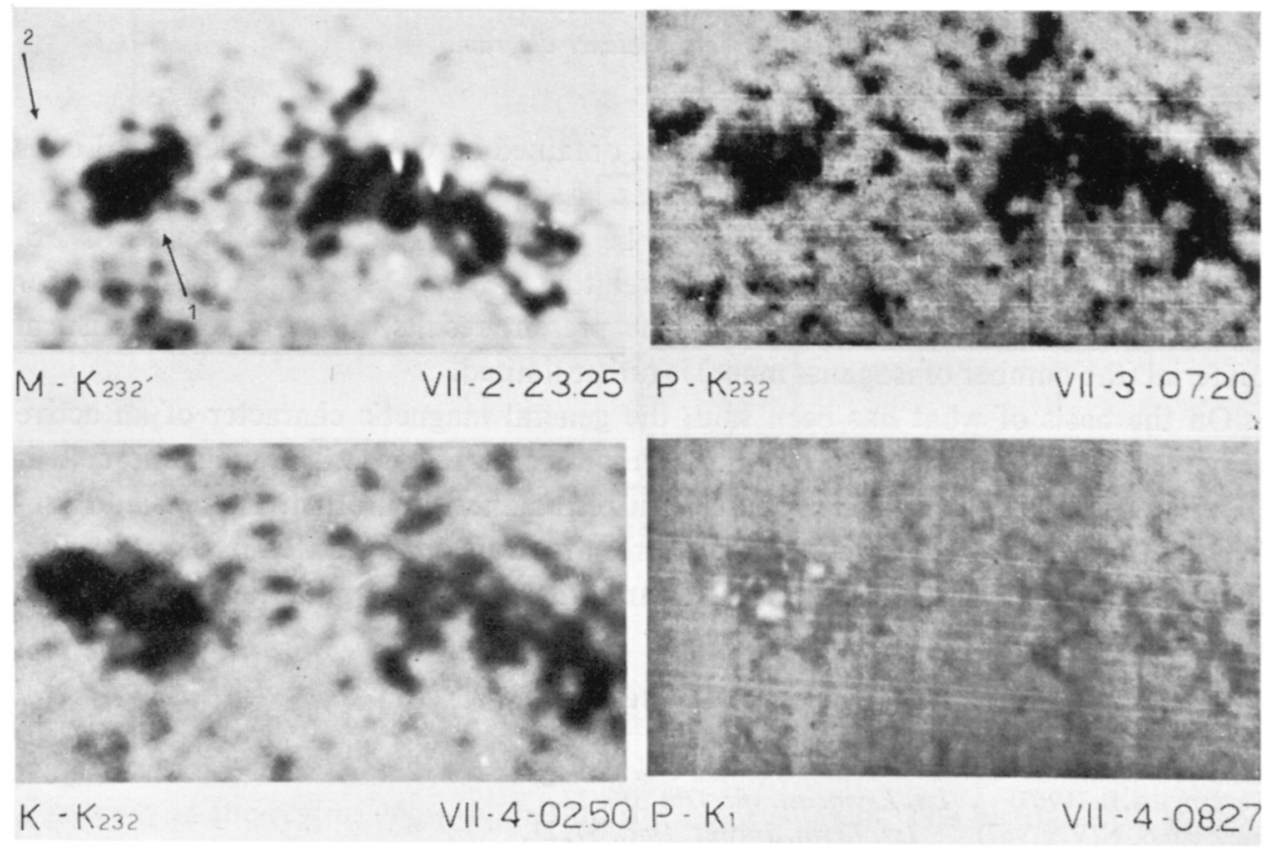

Fig. 1. PF Region McMath 8362 (June-July 1966). 1 =First center born on the solar disk on June 28, $2=$ Second center born on the solar disk on July 2, $A=$ Arcetri; $K=$ Kodaikanal; $M=$ Manila; $P=$ Paris.

* Presented by T. Fortini.

Kiepenheuer (ed.), Structure and Development of Solar Active Regions, 50-55. I.A.U. 
of an old region on June 28; the second one, two degrees East in longitude, started in a less disturbed area on July 2. Due to the closeness of the two centers, the Eastern one, on developing from East toward West, merged with the first center. Therefore, after July 4, two plages looked like one entity (Figure 1). The whole sunspot group (Rome 4369) was initially composed by two different groups, born successively in the first and in the second center (Figure 2). It is probable in this case that the merg-

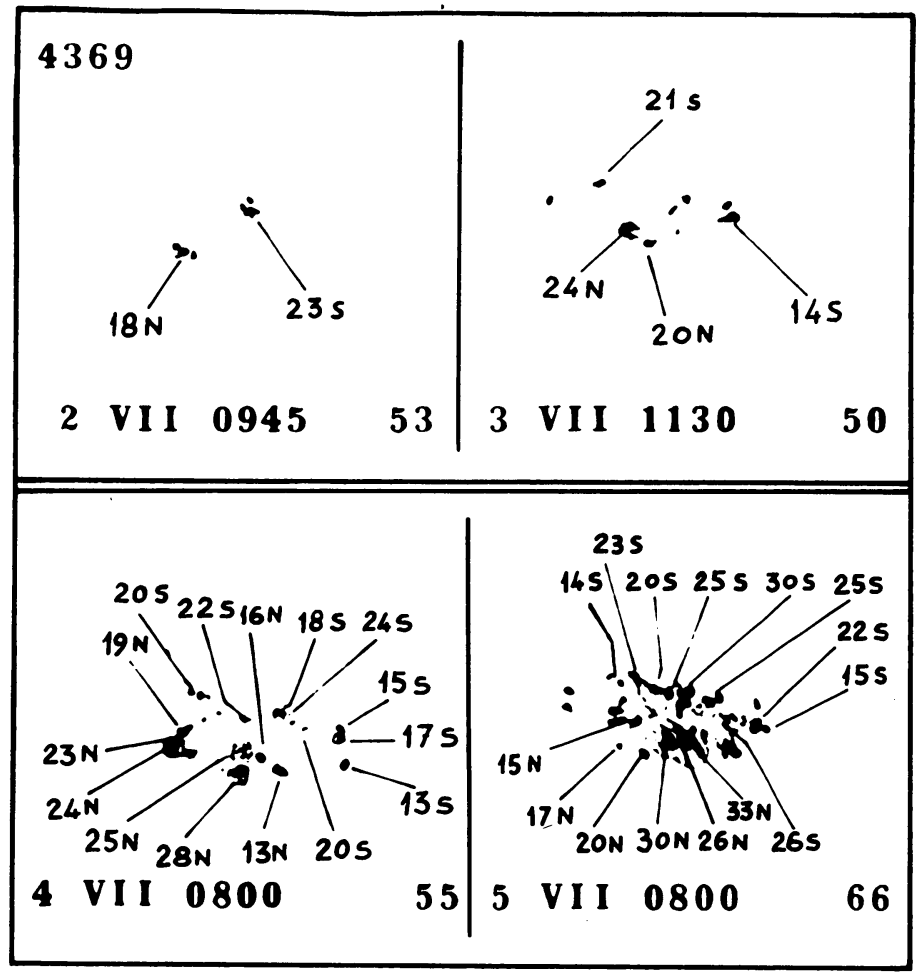

FIG. 2. PF Region McMath 8362. Sunspots magnetic configuration. Rome Observatory Magnetic Observations.

ing of the two centers, maybe favoured by their particular inclination to the solar equator, has lead to the morphological and magnetic configuration of two rows of sunspots with opposite magnetic polarities characteristic of many proton centers (Avignon et al., 1964). Therefore it was interesting to examine if the above circumstance, namely the merging of two or more active centers, is often or always verified during the formation of the PF regions.

With this purpose in mind, we have examined the PF regions occurred in the period January 1966 - May 1967, listed in Table 1. Only two regions were born on the solar disk; of these we have just now discussed the 1966 June-July region. The other region 
Table 1

List of polar cap absorption (PCA) events and associated proton flare (PF) regions (1 January 1966 - 31 May 1967)

\begin{tabular}{|c|c|c|c|c|}
\hline \multirow[t]{2}{*}{ PCA } & \multirow{2}{*}{$\begin{array}{c}\text { Region } \\
\text { (McMath Number) }\end{array}$} & \multicolumn{2}{|c|}{ Coord. } & Remarks \\
\hline & & $\lambda$ & $\varphi$ & \\
\hline 19663 III & 8174 & 130 & N 23 & born on the disk \\
\hline 23 III & $8207=8174$ & 138 & N 20 & \\
\hline 7 VII & 8362 & 210 & N 32 & born on the disk \\
\hline 28 VIII & 8461 & 185 & N 20 & \\
\hline 2 IX & 8461 & 185 & N 20 & \\
\hline $5 X$ & - & - & - & $\begin{array}{l}\text { not identified } \\
\text { (flare not observed) }\end{array}$ \\
\hline $196728 \mathrm{I}$ & 8659 & 269 & N 16 & \\
\hline 2 III & 8704 & 300 & N 22 & \\
\hline $11 \mathrm{III}$ & 8716 & 165 & S 22 & $\begin{array}{l}\text { suspected } \\
\text { (flare not observed) }\end{array}$ \\
\hline $28 \mathrm{~V}$ & 8818 & 228 & N 24 & \\
\hline
\end{tabular}

(McMath 8174, 8207 in the two successive solar rotations 1504, 1505 where it produced proton flares), was composed by two different centers born on the solar disk on February 20 and February 22, 1966 (Figure 3). Also in this case it is easy to separate the whole sunspot group in two distinct groups, at least during the first days (Figure 4). The region brightened and greatly increased after February 26. At the West-limb passage the region was already quite active. The preliminary Report of the Solar Activity of the High Altitude Observatory at Boulder referred that the region was "noteworthy for flares, bright surges, very strong coronal emission at $\lambda$ 5303, yellow line emission and moderate to strong radio emission at $9 \cdot 1 \mathrm{~cm}$ ". The Proton Flare occurred on March 3. The time of the elaboration of the PF event from the birth of the centers is almost the same as in the case of the PF region of July 1966 (Figure 5). During the second passage on the solar disk the center produced again a proton flare. It is hard to guess what happened in the invisible hemisphere. We have not considered this late activity of the region.

All the other regions we have studied until now have not be seen at their birth. When observed after the East-limb passage, all of them presented a complicated magnetic configuration, which always could be interpreted as originated by the mixing of two or more components.

From the other point of view we have also examined if the merging of two or more different centers is determinant in the production of the PF's. For the time being we have examined all Calcium observations for the first six months of 1967. We have found only one case of two fairly close centers born on the visible solar hemisphere. They have not interacted. In other few cases we observed centers born in the proximity 

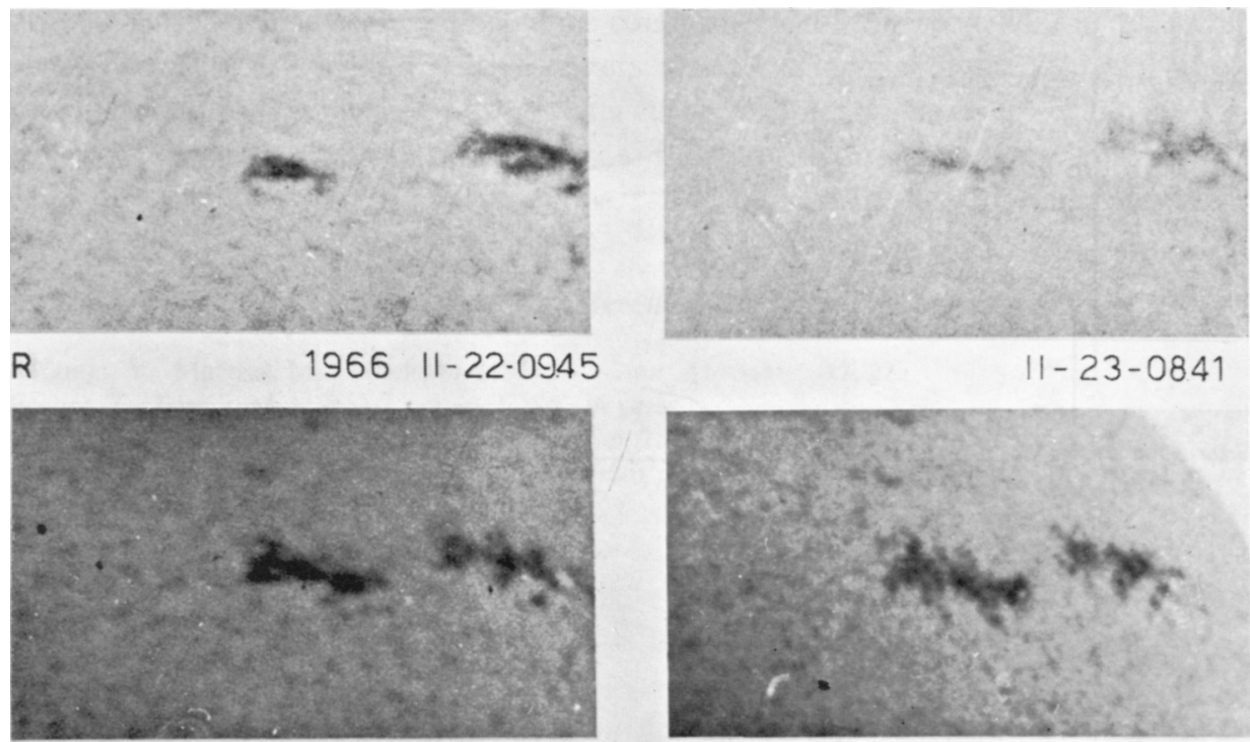

$11-24-11.10$
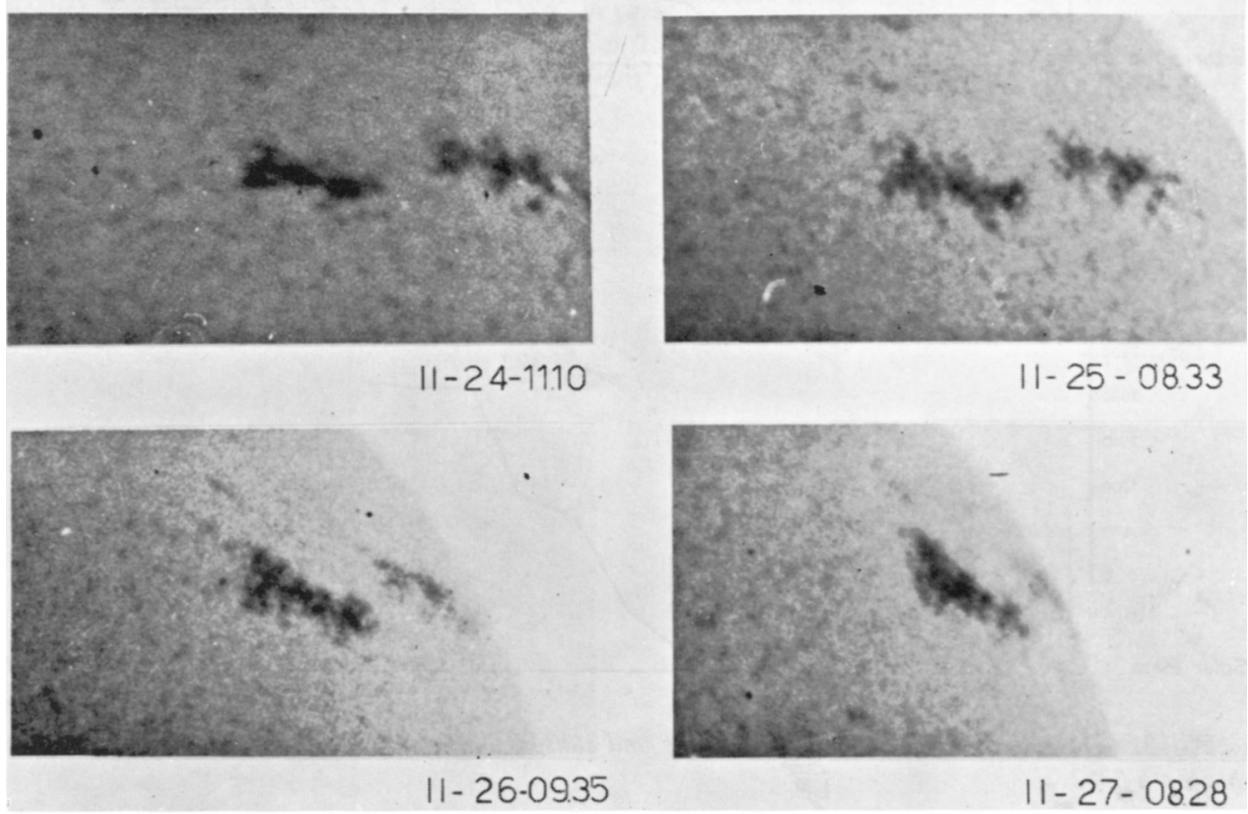

FIG. 3. PF Region McMath 8174 (February-March 1966). $R=$ Roma.

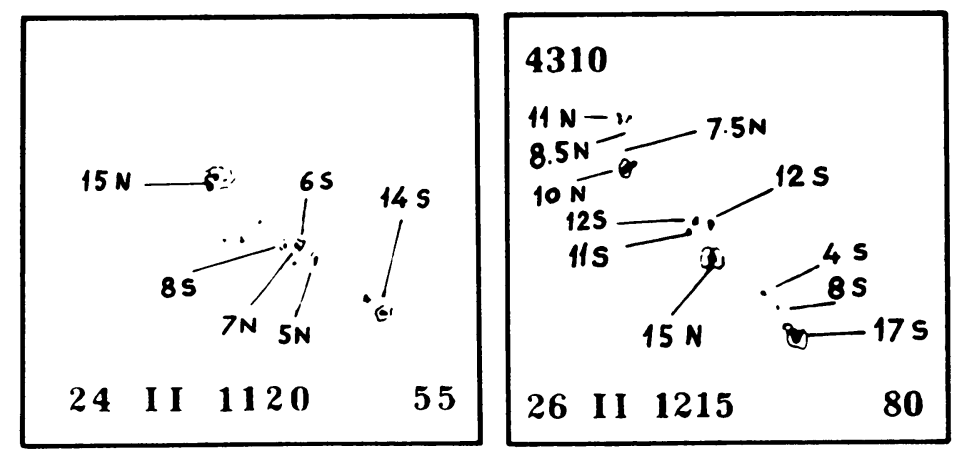

FIG. 4. PF Region McMath 8174. Sunspots magnetic configuration. Rome Observatory Magnetic Observations. 

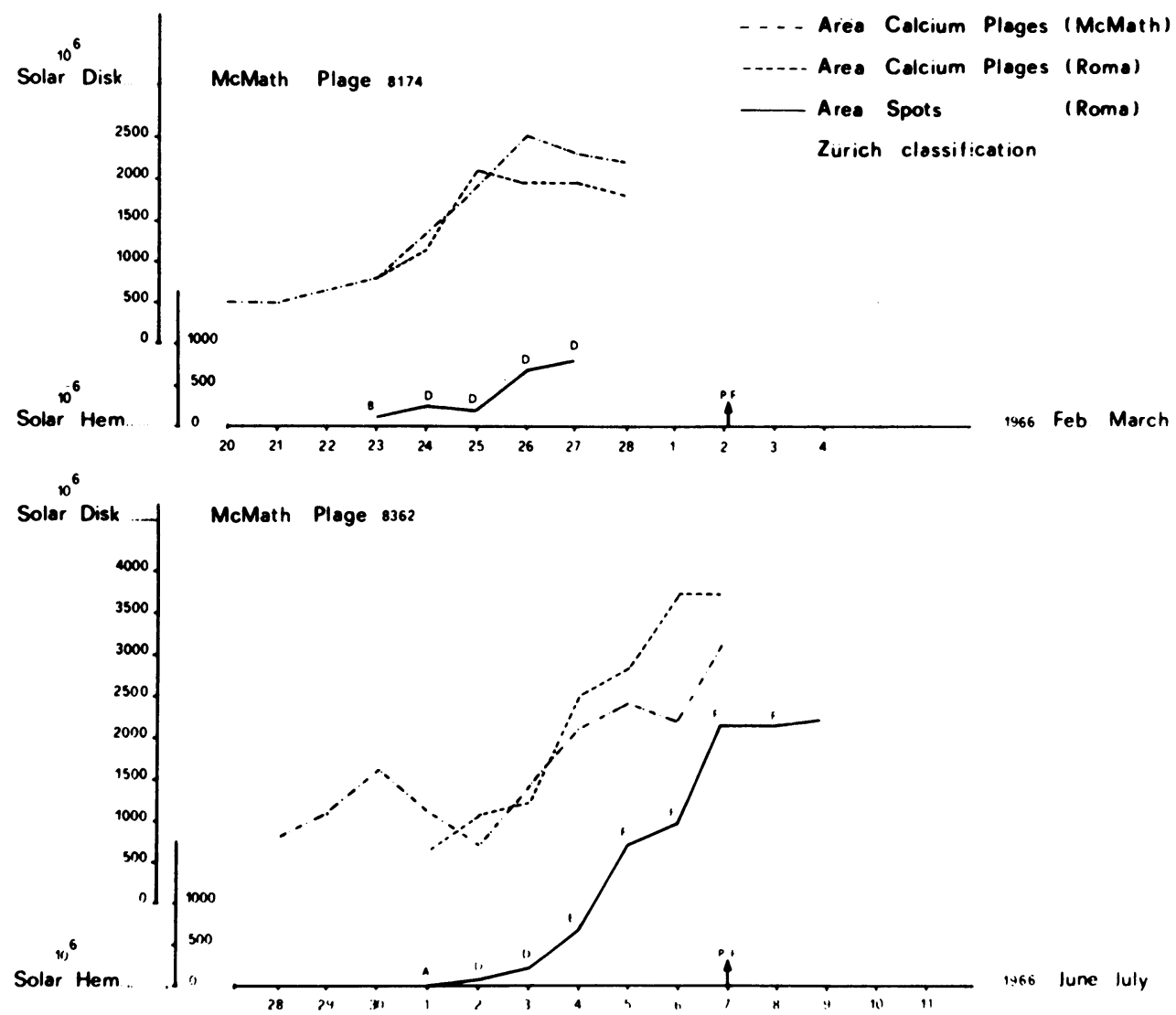

Fig. 5. Development of the Calcium plages and sunspots for the PF Regions McMath 8174 and McMath 8362.

of mature or decaying regions. In these cases too the centers have not interacted.

It shows, at our advice, that the closeness of two centers is, maybe, a necessary but not a sufficient condition for their interaction. Some other parameters, like the relative position (Martres, 1968), the inclination to the solar equator, the relative age of the interacting centers or something else, should play a role in the formation of the PF magnetic configuration. The knowledge of these parameters would be useful in the actual problem of forecasting the solar activity and particularly the proton flares.

On concluding our examination of the regions sites of the PF events in the period January 1966 - May 1967, we note (1) that the only two regions, developed on the solar disk, have been composed by two distinct centers; (2) the spot configuration of the regions not born on the visible hemisphere is not inconsistent with the fact that they have been originated by two or more separated centers; (3) the circumstance that 
the particular morphologic and magnetic configuration of the PF regions is due to the superposition of two or more active centers is also not inconsistent with the observation (Švestka, 1967) that the proton events occur in supercomplexes of regions. It is in fact more probable that the rather unusual fusion of two or more very close centers happen in the clustering of active regions, rather than in the less spotted areas of the solar surface.

\section{References}

Avignon, Y., Martres, M.J., Pick, M. (1964) Ann. Astrophys., 27, 23.

Fortini, T., Torelli, M. (1968) Ann. IQSY, in press.

Martres, M.J. (1968) in the present volume, p. 25.

Martres, M.J., Michard, R., Soru-Iscovici, I. (1966) Ann. d'Astrophys., 29, 245.

Svestka, Z. (1967) COSPAR, London. 